\title{
Enhanced gastric mucosal haemostasis after upper gastrointestinal haemorrhage
}

\author{
M C Allison, G M Fullarton, I L Brown, G P Crean, K E L McColl
}

\begin{abstract}
An endoscopic technique for the measurement of gastric mucosal bleeding time has been developed to study gastric haemostasis in patients with acute upper gastrointestinal haemorrhage. The relation of gastric mucosal bleeding time to skin bleeding time and nonsteroidal anti-inflammatory drug usage was examined in 61 control patients and in 47 patients presenting with bleeding peptic ulcers or erosions. Gastric mucosal bleeding time was shorter in patients with haemorrhage (median 2 minutes, range $0-5$ minutes) than in the control group (median 4 minutes, range 2-8 minutes) $(\mathbf{p}<0.001)$. Skin bleeding times were similar in the two groups (medians 4 minutes in patients with haemorrhage and 4.5 minutes in controls). In 21 patients with haemorrhage who were taking non-steroidal anti-inflammatory drugs, the median gastric mucosal bleeding time $(2.5$ minutes, range 1.0-5.0 minutes) was similar to that in 26 patients with haemorrhage not associated with these drugs ( $2 \cdot 0$ minutes, range 0.0-5.0 minutes). These results show that gastric mucosal haemostasis is accelerated in response to haemorrhage in the upper gastrointestinal tract, even in patients taking nonsteroidal anti-inflammatory drugs. This enhanced gastric haemostasis probably reflects a local protective response to minimise blood loss from the bleeding lesion.
\end{abstract}

Approximately $80 \%$ of acute upper gastrointestinal haemorrhages stop spontaneously. This is surprising, because the acidic environment of the upper gastrointestinal tract is not conducive to haemostasis. Platelet aggregation and plasma coagulation are abolished in vitro at $\mathrm{pH}<5 \cdot 4$. Furthermore, gastric juice is abundant in pepsin, which is a potent fibrinolytic agent in an acid medium of $\mathrm{pH}<4 .{ }^{23} \mathrm{We}$ have recently suggested that previously unrecognised physiological mechanisms may exist to facilitate haemostasis in the upper gastrointestinal tract. ${ }^{+}$In order to

of Medicine and

Therapeutics, and Departments of Surgery and Pathology, Western Infirmary, Glasgow; and Gastrointestinal Centre, Southern General Hospital, Glasgow M C Allison G M Fullarton

I L Brown

G P Crean

K E L McColl

Correspondence to:

Dr K E L McColl, University

Dr K E L McColl, University

Department of Medicin

Infirmary, Glasgow G11 6NT.

Accepted for publication

17 August 1990
TABLE I Demographic details of patients included in this study

\begin{tabular}{lcc}
\hline & Bleeding group & Control group \\
\hline No of patients & 47 & 61 \\
Mean age & 56 & 50 \\
Sex distribution & $35 \mathrm{M}, 12 \mathrm{~F}$ & $32 \mathrm{M}, 29 \mathrm{~F}$ \\
Mean blood pressure & $114 / 75$ & $116 / 74$ \\
Mean haematocrit & $0 \cdot 30$ & $0 \cdot 45$ \\
Mean platelet count $\left(\times 10^{4} / \mathrm{I}\right)$ & 274 & 289 \\
Mean KCCT (seconds) & 41 & 45 \\
On H, antagonists & $10(21 \%)$ & $29(48 \%)$ \\
Alcohol abusers & $9(19 \%)$ & $3(5 \%)$ \\
On aspirin & $6(13 \%)$ & $2(3 \%)$ \\
On other NSAIDs & $15(32 \%)$ & $7(11 \%)$ \\
\hline
\end{tabular}

$\mathrm{KCCT}=$ kaolin cephalin clotting time; $\mathrm{NSAID}=$ non-steroida anti-inflammatory drugs. investigate the possibility that gastric haemostasis is altered in patients presenting with upper gastrointestinal haemorrhage, we have developed and evaluated a direct visual endoscopic method for the determination of gastric mucosal bleeding time. The relation of the mucosal bleeding time to the skin bleeding time has been investigated in a control group and in consecutive patients presenting with haematemesis and melaena caused by bleeding peptic ulcers or erosions. In addition, we have examined whether these measures of haemostasis are affected by preceding non-steroidal anti-inflammatory drug (NSAID) intake in patients with haemorrhage.

\section{Methods}

PATIENTS WITH ACUTE UPPER GASTROINTESTINAL HAEMORRHAGE

Between August 1988 and September 1989, 47 patients admitted to hospital with acute upper gastrointestinal haemorrhage were examined. All patients fulfilled the following criteria for haemorrhage: (1) passage of melaena stool between the time of admission and the time of endoscopy or fresh or altered blood in the stomach at the time of endoscopy, or both; and (2) endoscopic finding of a benign non-variceal lesion in the upper gastrointestinal tract with active bleeding or stigmata of recent haemorrhage. There were 29 patients with duodenal ulcer, 11 with gastric ulcer, four with gastric erosions, and three with Mallory-Weiss tears. Twelve patients were actively bleeding at the time of endoscopy. Six (13\%) had been taking aspirin regularly, and the median time between the last aspirin dose and endoscopy was 36 hours (range 12-48 hours). Fifteen (32\%) were taking non-aspirin NSAIDs, having taken their last dose a median of 24 hours before endoscopy (range 12-96 hours). Demographic details of the patients are given in Table I.

\section{NON-BLEEDINGCONTROLGROUP}

Sixty one patients presenting for routine diagnostic endoscopy agreed to participate as controls. Recruitment of patients into this group was stratified for age in order to examine the possible effects of this variable on haemostasis. Information on control patients is given in Table $I$. Two (3\%) had been taking aspirin regularly and seven $(11 \%)$ were taking non-aspirin NSAIDs. Endoscopy showed no abnormality in 29 patients, active gastric ulcer in six, healed gastric ulcer in three, duodenal ulcer in seven, gastritis in three, duodenitis in three, gastric erosions in three, multiple peptic ulcers in one, and oesophagitis in six patients. 

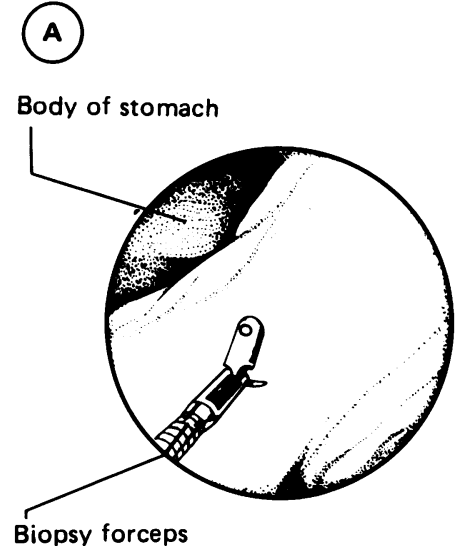
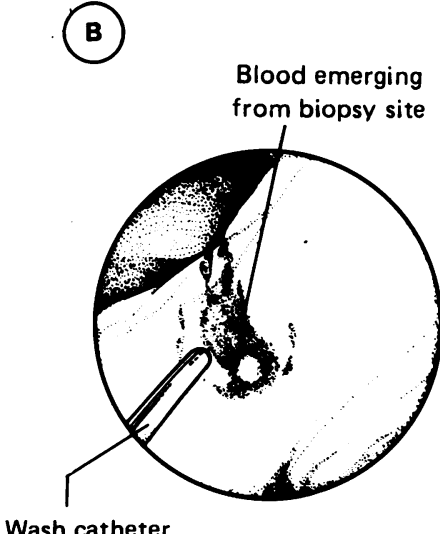

(c)

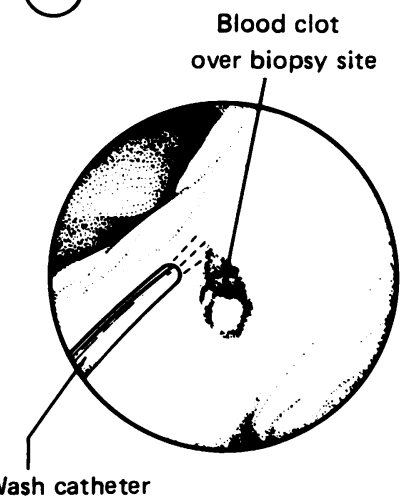

Figure 1: Diagrammatic illustration of the technique for assessment of gastric mucosal bleeding time. The explanation is given in the methods section.

\section{EXCLUSION CRITERIA}

Patients with haemorrhage were not included if there was clinical evidence of hypovolaemia or shock at the time of endoscopy (systolic blood pressure $<90 \mathrm{mmHg}$, pulse rate $>120 /$ minute or poor peripheral perfusion, or all three). Other factors precluding inclusion into either group were: known or suspected liver disease or portal hypertension, renal failure (serum creatinine $>250 \mu \mathrm{mol} / \mathrm{l}$ ), previous partial gastrectomy, endoscopic evidence of incisural gastritis or ulceration, upper gastrointestinal malignancy, primary haematological or haemorrhagic disorder, thrombocytopenia (platelet count $\left.<100 \times 10^{\%} / 1\right)$ or prior treatment with anticoagulants or dipyridamole.

\section{STUDY DESIGN}

All patients presenting to the Western Infirmary with suspected upper gastrointestinal haemorrhage are endoscoped within 24 hours of admission by members of a designated haematemesis management team. Before endoscopy, written, informed consent was obtained from patients who were agreeable to participating in the study if subsequently found to fulfil the inclusion criteria. Drug and alcohol histories were recorded for each patient. Pulse and blood pressure were checked immediately before diagnostic endoscopy. Within one hour of endoscopy and gastric mucosal bleeding time determination, blood was taken for estimation of haematocrit, platelet count, and kaolin cephalin clotting time. The quantity of any blood transfusion before endoscopy was noted. Finally, the skin bleeding time was determined within three hours of endoscopy by an investigator who was unaware of the diagnosis or the gastric mucosal bleeding time result. An identical study plan was used for the control patients.

\section{SKIN BLEEDING TIME}

This was measured with a disposable spring loaded instrument, the Simplate II bleeding time device (Organon Teknika, Belgium). The bleeding time was determined from standard incisions on the flexor surface of the proximal forearm while a sphygmomanometer cuff remained inflated at $40 \mathrm{mmHg}$. Previous studies using this method have shown reproducible results, comparable with those obtained by the template method, and have shown prolongation of the bleeding time with aspirin ingestion. ${ }^{5}$ The manufacturers give a normal range for skin bleeding time of 2-9 minutes. This range is in keeping with the results of a large study, in which it is also suggested that bleeding time decreases with age. ${ }^{6}$

\section{GASTRIC MUCOSAL BLEEDING TIME}

The following method was devised for the evaluation of gastric mucosal haemostasis. The patient is premedicated for endoscopy in the standard manner with intravenous diazepam (Diazemuls, KabiVitrum, UK), and given intravenous hyoscine-N-butylbromide, $20 \mathrm{mg}$ (Buscopan, Boehringer Ingleheim Ltd, UK) to minimise gastric peristalsis. After completion of the diagnostic part of the procedure, the stomach is submaximally distended, and the endoscope partly retroflexed in the gastric antrum so that a directly en face view of the angular incisura is obtained. Once it has been confirmed that the mucosa covering this region looks normal, a pair of FB24K pinch biopsy forceps (Olympus Corporation, Tokyo, Japan) is orientated longitudinally onto the angular apex (Fig 1A). A biopsy specimen is taken, and blood emerging from the biopsy site is seen to track with gravity in a retrograde fashion along the lesser curve and into the body of the stomach. The blood and clot adjacent to the biopsy site is carefully washed away with saline every 30 seconds using a wash catheter (PW-1L, Olympus), care being taken to avoid disturbing the biopsy site itself (Figure 1B). The gastric mucosal bleeding time is the time from biopsy to cessation of bleeding (end point illustrated in Fig 1C). This time was recorded to the nearest 30 seconds, as was the case with the skin bleeding time. The method employs some of the principles that underly skin bleeding time measurement, namely determination of the time taken for cessation of bleeding from a standard site after a standard incision.

All gastric mucosal bleeding time measurements were performed by one of two endoscopists (MA, GF). A pilot study using an endoscope and teaching extension was undertaken by these investigators to examine their interobserver variation in determining bleeding 


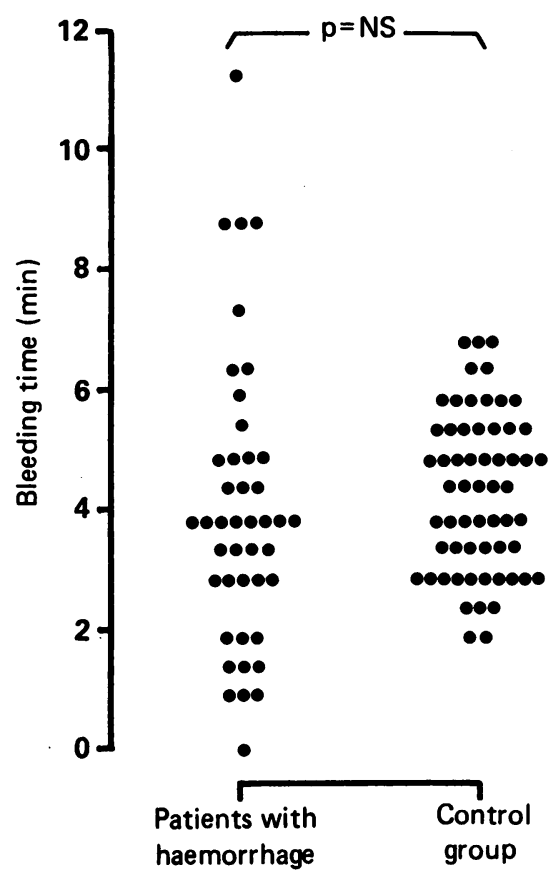

Skin bleeding times

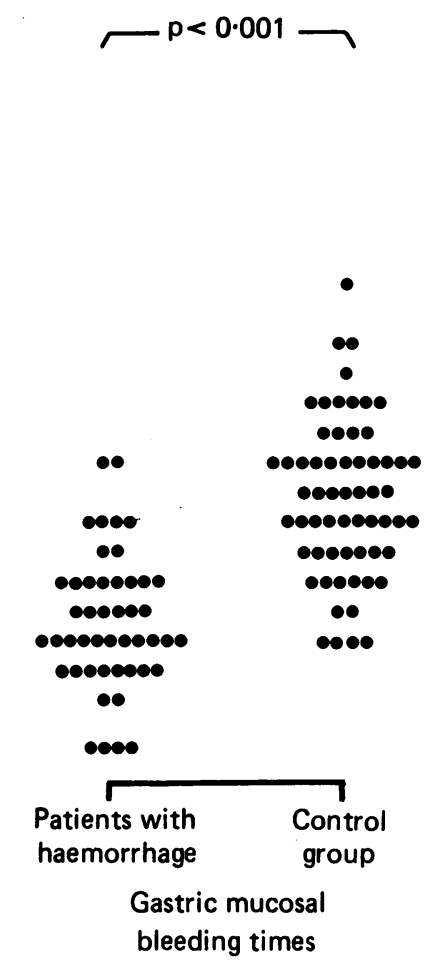

bleeding times
Figure 2: Skin and gastric mucosal bleeding times in 47 patients with upper gastrointestinal haemorrhage and 61 control patients.

time in 12 simultaneously studied control patients. Median gastric mucosal bleeding time in these patients was found to be 4 minutes by one observer and 4.5 minutes by the other. The median difference in their interpretations was 0.5 minutes (range 0.0-1.5 minutes). There was good interobserver correlation for these gastric mucosal bleeding time determinations $(r=0.76$, $\mathrm{p}<0.01$ ).

\section{INCISURAL BIOPSY SPECIMENS}

The single biopsy specimen taken from the site of gastric mucosal bleeding time determination was fixed in formaldehyde, sectioned, and stained according to standard methods with haematoxylin and eosin, and examined by light microscopy. They were interpreted as normal or gastritis without access to clinical information.

\section{STATISTICAL ANALYSIS}

Results of skin bleeding times and gastric mucosal bleeding times are not continuous variables, and are therefore expressed as medians and ranges. The results in the patients with haemorrhage and in the control group, however, conformed to approximately normal distribu- tions, and a total of 108 patients were studied (Fig 2). Therefore, the significances of observed differences between mean bleeding times in these two groups were examined using Student's $t$ test. Graphs were plotted to examine the degrees of correlation between the bleeding times and the variables which might potentially affect them, and significances of observed correlations were examined using Spearman's rank correlation method where appropriate. Results were considered significant when $p<0.05$. The study was approved by the local hospital ethics committee.

\section{Results}

NON-BLEEDINGCONTROLGROUP

The median skin bleeding time in the control patients without haemorrhage was 4.5 minutes (range 2-7 minutes), and their median gastric mucosal bleeding time was found to be four minutes (range 2-8 minutes) (Fig 2). Subgroup analysis did not show any effect of age or preceding $\mathrm{H}_{2}$ antagonist treatment on either skin or gastric mucosal haemostasis (Table II). There was no correlation between skin and gastric mucosal bleeding time $(r=-0 \cdot 23, p=N S)$. For the nine patients taking NSAIDs, skin and gastric bleeding times (medians 3.5 minutes and 4.0 minutes respectively) were similar to those in the 52 patients not taking these drugs (median skin and gastric mucosal bleeding times both 4.5 minutes).

\section{PATIENTS WITH ACUTE UPPER GASTROINTESTINAL} HAEMORRHAGE

There was a broader range of skin bleeding times in these patients (0-11.5 minutes) than in the control group $(2 \cdot 0-7 \cdot 0$ minutes $)$ but the median values in the two groups did not differ significantly ( 4 minutes in bleeders $v 4.5$ minutes in the control group - Fig 2). No relation between skin bleeding time and haematocrit was observed.

Gastric mucosal bleeding time was found to be significantly shorter $(\mathrm{p}<0.001)$ in the patients with recent haemorrhage (median 2 minutes, range $0-5$ minutes) than in the non-bleeding control group (median 4 minutes, range 2-8 minutes) (Fig 2). Four patients with recent haemorrhage failed to bleed after incisural biopsy. Acceleration of gastric haemostasis in response to recent haemorrhage was observed in all subgroups of patients, even in those with a history of preceding aspirin or NSAID intake (Table III). The median gastric mucosal bleeding time was $2 \cdot 5$ minutes in those taking NSAIDs compared with 2.0 minutes in those not taking

TABLE II Subgroup analysis of skin and gastric mucosal bleeding times in non-bleeding control patients

\begin{tabular}{|c|c|c|c|c|c|c|c|c|}
\hline & \multicolumn{4}{|l|}{$\operatorname{Age}(y r s)$} & \multirow{2}{*}{$\begin{array}{l}\text { On NSAID } \\
\text { (including } \\
\text { aspirin) }\end{array}$} & \multirow{2}{*}{$\begin{array}{l}\text { Not on } \\
\text { NSAID }\end{array}$} & \multirow{2}{*}{$\begin{array}{l}\text { On } H_{\text {antagonist }} \\
\text { antal }\end{array}$} & \multirow{2}{*}{$\begin{array}{l}\text { Not on } H \\
\text { antagonist }\end{array}$} \\
\hline & Overall & $<40$ & $40-65$ & $>65$ & & & & \\
\hline $\begin{array}{l}\text { No of patients } \\
\text { Median gastric mucosal } \\
\text { bleeding time (min) }\end{array}$ & $\begin{array}{l}61 \\
4 \cdot 0\end{array}$ & $\begin{array}{l}20 \\
4 \cdot 0\end{array}$ & $\begin{array}{l}21 \\
5 \cdot 0\end{array}$ & $\begin{array}{l}20 \\
3 \cdot 5\end{array}$ & $\begin{array}{l}9 \\
4 \cdot 0\end{array}$ & $\begin{array}{l}52 \\
4 \cdot 5\end{array}$ & $\begin{array}{l}28 \\
+\cdot 0\end{array}$ & $\begin{array}{l}33 \\
4 \cdot 5\end{array}$ \\
\hline $\begin{array}{l}\text { Range } \\
\text { Median skin bleeding } \\
\text { time (min) }\end{array}$ & $\begin{array}{l}2 \cdot 0-8 \cdot 0 \\
4 \cdot 5\end{array}$ & $\begin{array}{l}2 \cdot 0-7 \cdot 0 \\
4 \cdot 5\end{array}$ & $\begin{array}{l}2 \cdot 0-7 \cdot 0 \\
4 \cdot 5\end{array}$ & $\begin{array}{l}2 \cdot 0-8 \cdot 0 \\
5 \cdot 0\end{array}$ & $\begin{array}{l}3 \cdot 5-5 \cdot 5 \\
3 \cdot 5\end{array}$ & $\begin{array}{l}2 \cdot 0-8.0 \\
4 \cdot 5\end{array}$ & $\begin{array}{l}2 \cdot 0-7 \cdot 0 \\
+\cdot 0\end{array}$ & $\begin{array}{l}2 \cdot 0-8 \cdot 0 \\
\cdot 0\end{array}$ \\
\hline Range & $2 \cdot 0-7 \cdot 0$ & $2 \cdot 5-7 \cdot 0$ & $2 \cdot 0-6 \cdot 0$ & $2 \cdot 5-6 \cdot 0$ & $2 \cdot 0-5 \cdot 5$ & $2 \cdot 0-7 \cdot 0$ & $2 \cdot 0-7 \cdot 0$ & $2 \cdot 0-7 \cdot 0$ \\
\hline
\end{tabular}


TABLE III Subgroup analysis of skin and gastric mucosal bleeding times in patients with upper gastrointestinal haemorrhage

\begin{tabular}{|c|c|c|c|c|c|c|c|c|c|}
\hline & Overall & $\begin{array}{l}\text { On NSAID } \\
\text { (including } \\
\text { aspirin) }\end{array}$ & $\begin{array}{l}\text { Not on } \\
\text { NSAID }\end{array}$ & $\begin{array}{l}\text { Alcohol } \\
\text { abusers }\end{array}$ & Non-abusers & Transfused & $\begin{array}{l}\text { Not } \\
\text { transfused }\end{array}$ & $\begin{array}{l}\text { Active bleed } \\
\text { or visible } \\
\text { vessel }\end{array}$ & $\begin{array}{l}\text { Minor } \\
\text { stigmata }\end{array}$ \\
\hline $\begin{array}{l}\text { No of patients } \\
\text { Median gastric } \\
\text { mucosal } \\
\text { bleeding time } \\
\text { (min) }\end{array}$ & $\begin{array}{l}47 \\
2 \cdot 0\end{array}$ & $\begin{array}{l}21 \\
2 \cdot 5\end{array}$ & $\begin{array}{l}25 \\
2 \cdot 0\end{array}$ & $\begin{array}{l}9 \\
2 \cdot 0\end{array}$ & $\begin{array}{l}38 \\
2 \cdot 0\end{array}$ & $\begin{array}{l}19 \\
2 \cdot 0\end{array}$ & $\begin{array}{l}28 \\
2 \cdot 0\end{array}$ & $\begin{array}{l}26 \\
2 \cdot 0\end{array}$ & $\begin{array}{l}21 \\
2 \cdot 5\end{array}$ \\
\hline $\begin{array}{l}\text { Range } \\
\text { Median skin } \\
\text { bleeding time } \\
(\mathrm{min})\end{array}$ & $\begin{array}{l}0 \cdot 0-5 \cdot 0 \\
4 \cdot 0\end{array}$ & $\begin{array}{l}1 \cdot 0-5 \cdot 0 \\
4 \cdot 0\end{array}$ & $\begin{array}{l}0 \cdot 0-3 \cdot 5 \\
4 \cdot 0\end{array}$ & $\begin{array}{l}0 \cdot 0-5 \cdot 0 \\
5 \cdot 5\end{array}$ & $\begin{array}{l}0 \cdot 0-5 \cdot 0 \\
4 \cdot 0\end{array}$ & $\begin{array}{l}0 \cdot 0-5 \cdot 0 \\
4 \cdot 0\end{array}$ & $\begin{array}{l}0 \cdot 0-4 \cdot 0 \\
4 \cdot 5\end{array}$ & $\begin{array}{l}0 \cdot 0-5 \cdot 0 \\
4 \cdot 0\end{array}$ & $\begin{array}{l}1 \cdot 5-5 \cdot 0 \\
5 \cdot 0\end{array}$ \\
\hline Range & $0.0-11.5$ & $1 \cdot 5-11 \cdot 5$ & $0 \cdot 0-9 \cdot 0$ & $1 \cdot 0-9 \cdot 0$ & $0 \cdot 0-11 \cdot 5$ & $1 \cdot 5-11 \cdot 5$ & $0.0-9.0$ & $0 \cdot 0-11 \cdot 5$ & $1 \cdot 0-9 \cdot 0$ \\
\hline
\end{tabular}

NSAIDs $(\mathrm{p}=\mathrm{NS})$. Gastric mucosal bleeding time values in patients with significant haemorrhage (requiring transfusion, actively bleeding, or major stigmata of recent haemorrhage at endoscopy, or both) were similar to those in patients with less severe haemorrhage (no transfusion requirement, minor endoscopic stigmata) (Table III).

\section{COAGULATION PARAMETERS AND HISTOLOGY}

KCCT values were similar in patients with haemorrhage and controls (medians 41 and 45 seconds respectively, $p=N S$ ). The proportions of incisural biopsy specimens showing histological evidence of gastritis were similar in the two groups of patients $(57 \%$ in patients with haemorrhage and $66 \%$ in controls). Gastric mucosal bleeding time results were unaffected by kaolin cephalin clotting time values or histological findings.

\section{Discussion}

There have been several studies of systemic factors that may contribute to haemostasis in patients with non-variceal upper gastrointestinal haemorrhage. ${ }^{7-9}$ In addition, the effect of gastric acidity on fibrinolytic activity and clot digestion has been examined..$^{1-3} 10$ There is, however, little published information on gastric mucosal haemostasis and, to our knowledge, no studies have examined gastric haemostatic processes in patients presenting with haematemesis and melaena. This study shows that gastric haemostasis is enhanced in patients presenting with upper gastrointestinal haemorrhage.

There are several possible explanations for accelerated gastric haemostasis in patients with upper gastrointestinal haemorrhage. Firstly, splanchnic vasoconstriction may occur even in the absence of generalised vasoconstriction or shock. A second factor that may contribute to enhanced haemostasis is inhibition of gastric secretion in response to haemorrhage; reduced intragastric acidity and pepsin output would be expected to facilitate local platelet aggregation and stable clot formation. ${ }^{1-3}$ Chandler and Watkinson have shown a temporary achlorhydria in patients with intraduodenal haemorrhage, ${ }^{11}$ and we have recently shown inhibition of gastric secretion and motility in response to simulated intraduodenal haemorrhage. ${ }^{4} \mathrm{~A}$ third possibility is that haemorrhage could act as a stimulus to systemic platelet aggregation or an increase in platelet mass. In these circumstances, the skin bleeding time might be expected to shorten, ${ }^{12}$ a finding which was not observed in this study. Evidence against increased local platelet aggregation being responsible for enhanced gastric haemostasis comes from experiments in animals by Whittle et al. ${ }^{13}$ These workers showed that gastric mucosal bleeding times after standard mucosal incisions were unaltered by infusion of prostacyclin into the mesenteric arterial supply. Infusion of heparin, however, did prolong gastric mucosal bleeding in this model. The conclusion of their study was that the arrest of gastric haemorrhage is primarily brought about by processes involving the coagulation system..$^{13}$ Local activation of coagulation pathways would provide yet another possible explanation for enhanced gastric haemostasis in response to haemorrhage.

Aspirin ingestion is a well known cause of a prolonged skin bleeding time. ${ }^{514}$ This effect is the result of interference with platelet aggregation, which may persist for more than seven days. ${ }^{15}$ The effect of aspirin on gastric mucosal haemostasis has been investigated previously. When given to volunteers at doses sufficient to prolong skin bleeding time, aspirin did not cause any increase in mucosal blood loss from gastric biopsy sites. ${ }^{16}$ In a more recent study, where gastric mucosal biopsy was followed by lavage, high dose aspirin led to prolonged gastric bleeding but placebo did not. ${ }^{17}$ Although only six patients with haemorrhage and two control subjects gave a history of recent aspirin ingestion in the present study, no evidence was found to suggest that this drug interferes with gastric haemostasis. The experiments of Whittle et al lend further support to the view that the inhibitory effect of aspirin on platelet aggregation does not delay mucosal haemostasis. ${ }^{13}$ These results do not exclude the possibility that platelet inhibition by aspirin is an important initial trigger for haemorrhage from pre-existing or drug induced mucosal lesions.

The effects of non-aspirin NSAIDs on platelet aggregation and haemostasis are less clear cut than those of aspirin itself There is general agreement that drugs such as indomethacin, ibuprofen, naproxen, and piroxicam inhibit aggregability in vitro, and that this effect persists for up to two days. ${ }^{15-20}$ However, the inhibition is less noticeable than that induced by aspirin, and skin bleeding times are reported to be only slightly prolonged by these drugs. ${ }^{18}$ The results of this study do not support the hypothesis that non-aspirin NSAIDs interfere with gastric haemostasis in patients presenting with upper 
gastrointestinal haemorrhage. A transient early prolongation of bleeding times may, however, have gone undetected because patients were studied a median of 24 hours after their last NSAID dose. Furthermore, it is possible that a drug induced inhibition of gastric haemostasis may have been outweighed by the observed shortening of gastric mucosal bleeding time after haemorrhage.

In conclusion, this study has shown that skin haemostasis is unaltered, yet gastric mucosal haemostasis is accelerated in patients with upper gastrointestinal haemorrhage, even in those taking NSAIDs. This may reflect a local physiological protective mechanism to facilitate haemostasis in the upper gastrointestinal tract. Further understanding of the mechanisms underlying gastric haemostasis may result in new approaches to the treatment of patients with upper gastrointestinal haemorrhage.

We thank the members of the Haematemesis Management Team at the Western Infirmary for allowing us to study their patients. at the Western Infirmary for allowing us to study their patients.
These include Mr F Kennedy, Mr C MacKay, Dr G Allan, Dr P These include Mr F Kennedy, Mr C MacKay, Dr G Allan, Dr P
Mills, Mr W Murray and Mr D Galloway. We are grateful to Dr N Mills, Mr W Murray and Mr D Galloway. We are grateful to Dr N Lucie and the Department of Haematology for their assistance. Our thanks to Mrs D Ronney and Mrs J MacDonald for preparing
the manuscript and diagrams; and to Dr D Sumner and Dr K Howie for statistical advice.

1 Green WF, Kaplan MM, Curtis LE, Levine PH. Effect of acid and pepsin on blood coagulation and platelet aggregation. Gastroenterology 1978; 74: 38-43.

2 Low J, Dodds AJ, Biggs JC. Fibrinolytic activity of gastroduodenal secretions - a possible role in upper gastrointestinal haemorrhage. Thromb Res 1980; 17: 819-30.

3 Wheatley KE, Poxon V, Dykes PW, Keighley MRB. Intragastric fibrinolysis and peptic ulcer disease [Abstract]. $G u t$ 1987; 28: A1402.
4 Fullarton GM, Boyd EJS, Crean GP, Buchanan K, McColl KEL. Inhibition of gastric secretion and motility by simulated upper gastrointestinal haemorrhage: a response to facilitate haemostasis? Gut 1989; 30: 156-60.

5 Kumar R, Ansell JE, Canoso RT, Deykin D. Clinical trial of a new bleeding-time device. Am $\mathcal{f}$ Clin Pathol 1978; 70: 642-5.

6 Macpherson CR, Jacobs P. Bleeding time decreases with age. Arch Pathol Lab Med 1987; 111: 328-9.

7 Blair SD, Janvrin SB, McCollum CN, Greenhalgh RM. Effect of early blood transfusion on gastrointestinal haemorrhage. Br $\mathcal{F}$ Surg 1986; 73: 783-5.

8 Leonard Jones $\mathrm{H}$, Ball RE, Jenkins LJ Jr, et al. Studies of systemic hemostatic factors in patients with bleeding duosystemic hemostatic factors in patients with ble
denal ulcer. Am $\mathcal{f}$ Gastroenterol 1961; 35: 243-57.

9 Biggs J, Hugh T, Dodds A. Tranexamic acid in upper gastrointestinal haemorrhage - a double-blind trial. Gut 1976; 17: 729-34.

10 Bodi T, Kazal LA. Some aspects of the pathophysiology and the multiple contributing factors in hemorrhage from the upper gastrointestinal tract. Am F Gastroenterol 1965; 44: 202-31.

11 Chandler GN, Watkinson G. Gastric aspiration in haematemesis. Lancet 1953; ii: 1170-5.

12 Milner PC, Martin JF. Shortened bleeding time in acute myocardial infarction and its relation to platelet mass. $B M \mathcal{F}$ 1985; 290: 1767-70.

13 Whittle BJR, Kauffman GL Jr, Moncada S. Hemostatic mechanisms, independent of platelet aggregation, arrest mechanisms, independent of platelet aggregation, arrest gastric m.

14 Meikle CH Jr, Kaneshiro MM, Maher JA, Weiner JM, Rappaport SI. The standardised normal Ivy bleeding tim and its prolongation by aspirin. Blood 1969; 34: 204 9

15 Lind SE. Prolonged bleeding time. Am f Med 1984; 77: 30512.

16 O'Laughlin JC, Hoftiezer JW, Mahoney JP, Ivey KJ. Does aspirin prolong bleeding time from gastric biopsies in man? Gastrointest Endosc 1981; 27: 1-5.

17 Daneshmend TK, Sharma HK, Hawthorne AB, Bhaakar NK, Hawkey CJ. A new measure, the gastric bleeding time prolongation by aspirin in humans [A bstract]. Gastroenterolprolongation by aspirin

18 McIntyre BA, Philp RB, Inwood MJ. Effect of ibuprofen on platelet function in normal subjects and hemophiliac platelet function in normal subjects and her

19 Cronberg S, Wallmark E, Soderberg I. Effect on platelet aggregation of oral administration of 10 non-steroidal analgesics to humans. Scand F Haematol 1984; 33: 155-9.

20 de Gaetano G, Deoneti MB, Garattini S. Drugs affecting platelet function tests. Thrombosis et Diathesis Haemorrhagica 1975; 34: 285-303. 